\title{
Differential proteomic response of Agaricus bisporus and Trichoderma aggressivum f. europaeum to Bacillus velezensis supernatant
}

\author{
Dejana Kosanovic • Maria Dyas • Helen Grogan • \\ Kevin Kavanagh
}

Accepted: 3 March 2021 / Published online: 10 March 2021

(C) Koninklijke Nederlandse Planteziektenkundige Vereniging 2021

\begin{abstract}
Trichoderma aggressivum, a mycopathogen causing green mould disease, is a major problem in Agaricus bisporus cultivation due to crop loss, and resistance to chemical fungicides. There is an urgent need for novel biological ways to control mycopathogens without affecting the growth of A. bisporus. Bacteria from the mushroom-casing environment were identified and tested for antagonistic effect on T. aggressivum. Bacillus velezensis produced a large zone of inhibition and its supernatant inhibited the growth of T. aggressivum [-37\%], and slightly stimulated $A$. bisporus growth [+2\%]. Label free quantitativeproteomic (LFQ) analysis of changes in the abundance of $T$. aggressivum proteins following exposure to $B$. velezensis supernatant indicated increased abundance of proteins associated with catabolic processing of amino acids (40-fold), amino oxidase proteins (14-fold), oxidoreductase proteins (13-fold, 4-fold) and hydrolases (3-fold). Proteins that decreased in relative abundance were antioxidants (29-fold), NTF2 domain containing protein (17-fold), 60S ribosomal protein L-13 (14-fold),
\end{abstract}

D. Kosanovic $\cdot$ M. Dyas $\cdot$ K. Kavanagh $(\bowtie)$

Department of Biology, Maynooth University, Maynooth, Co.

Kildare, Ireland

e-mail: Kevin.Kavanagh@mu.ie

H. Grogan

Teagasc, Horticulture Development Department, Ashtown

Research Centre, Dublin 15, Ireland glucoamylase proteins (13-fold), proteasome subunit proteins (11-fold) and other ribosomal proteins (9-fold). LFQ analysis revealed that exposing A. bisporus to $B$. velezensis supernatant led to a decrease in: prohibitin (13-fold, 6-fold), proteasomal proteins (11-fold), cytosolic adaptor domain containing protein (5-fold), aldehyde dehydrogenase (4-fold), ribosomal proteins (4fold), DLH domain-containing protein (4-fold) and PKS_ER domain containing protein (3-fold). The results indicate that $A$. bisporus was not under stress upon contact with $B$. velezensis. Whereas a detrimental effect of $B$. velezensis on T. aggressivum is shown by inhibition of growth and damage-preventing proteins and increased abundance of proteins associated with stress.

\section{Keywords Agaricus bisporus · Trichoderma aggressivum $\cdot$ Bacillus velezensis $\cdot$ Proteomics}

$\begin{array}{ll}\text { Abbreviations } \\ \text { FDR } & \text { False Discovery Rates } \\ \text { GO } & \text { gene ontology } \\ \text { SSDA } & \text { statistically significant differentially abundant } \\ \text { DEP } & \text { differentially expressed proteins } \\ \text { LFQ } & \text { Label free quantitative-proteomic } \\ \text { ME } & \text { malt extract } \\ \text { CYM } & \text { complete yeast media } \\ \text { SN } & \text { supernatant } \\ \text { MPN } & \text { Most probable number } \\ \text { SE } & \text { Standard error }\end{array}$




\section{Introduction}

The world mushroom industry is dominated by five species: shiitake (Lentinula sp.) (20\%), oyster mushrooms (Pleurotus spp.) (19\%), wood ear mushroom (Auricularia spp.) (17\%), common or white button mushroom (Agaricus bisporus (Lange) Imbach) (15\%) and Enoki mushrooms (Flammulina velutipes (Curtis) Singer) $(11 \%)$ with China accounting for $87 \%$ of total production (Royse et al. 2017). Outside of Asia, A. bisporus is the dominant species grown in North America and Europe (Royse et al. 2017) and the main horticultural crop in the Republic of Ireland (Alexander 2015). Cultivation of A. bisporus relies upon the use of a hybrid strain that was developed in 1980s, the Horst-U1 strain varieties. Thus, there is a lack of genetic diversity worldwide, making the global crop susceptible to attack from a variety of pathogens (Savoie et al. 2013).

Two sub-species of T. aggressivum (Samuels \& W Gams): T. aggressivum f. europaeum (biotype Th4) and T. aggressivum f. aggressivum (biotype Th2), are responsible for causing green mould disease of A. bisporus, which is visible as a green sporulating mould on the mushroom substrate surface (Kosanović et al. 2013). T. aggressivum can destroy a mushroom crop if it gets into freshly spawned Phase II compost. The pathogen is extremely well-suited to the mushroom growing conditions at this stage of production. It is fast growing when presented with carbohydrate-rich substrates and it is well suited to the growing temperatures of A. bisporus (Grogan 2008).

Mycopathogens such as green mould on mushroom crops are challenging to treat because both pathogen and its host are fungal (Grogan 2006; Potočnik et al. 2015). A limited number of chemical fungicides are officially approved for use against mushroom diseases, depending on local pesticide regulations, and currently include: prochloraz, metrafenone, thiabendazole and chlorothalonil (Grogan 2008; Kosanović et al. 2015; Potočnik et al. 2015). The continuous usage of fungicides as a disease control strategy on mushrooms farms can lead to the development of pathogen resistance and host sensitivity (Fletcher and Yarham 1976; Grogan and Gaze 2000; Romaine et al. 2005; Gea et al. 2005; Grogan 2006; Potočnik et al. 2015). Pesticide use worldwide is under scrutiny due to concerns about their impact on biodiversity, the environment and human health. In the EU, pesticide use is currently regulated by the Sustainable Use of Pesticides Directive (SUD) 2009/128/EC (Anon 2009), which advocates an integrated pest management (IPM) approach to pest and disease control. This involves many practices including pest prevention and monitoring, using sustainable biological or non-chemical methods where possible and using anti-resistance strategies to maintain effectiveness of products. There is an urgent requirement for more biological control products for the mushroom sector. Serenade ${ }^{\circledR}$ is a widely used bio-fungicide for many years containing non-pathogenic Bacillus velezensis strain QST 713 (Kosanović et al. 2013; Pandin et al. 2018) while Serifel ${ }^{\circledR}$ is a more recent product based on Bacillus amyloliquefaciens strain MBI600, both are approved for use against the mushroom pathogen Trichoderma aggressivum but there is little information on how they interact with the host and pathogen to achieve control (Kosanović et al. 2013).

Proteomics, the study of proteins and protein interactions in a cell or organism, is an advanced technology that allows a greater understanding of disease states in combination with bioinformatics. This technology can be used to give an insight into what is occurring upon contact between the host and the pathogen on the proteome level (Cho 2007). By identifying particular proteins that have been either over-expressed or underexpressed as a result of this contact, and determining affected biochemical pathways, it is possible to begin to build a picture of the exact mechanisms underlying the pathogenicity or defence mechanisms of a cell.

Since naturally occurring bacteria and fungi coexist and compete within the mushroom growing substrate, native Bacillus spp. are considered as potential alternatives to chemical control of green mould disease (Védie and Rousseau 2008; Kosanović et al. 2013; Potočnik et al. 2019). This paper details the testing of a supernatant derived from an environmental isolate of Bacillus velezensis as a potential biocontrol agent against green mould disease in A. bisporus cultivation. Bacteria supernatants, also known as culture filtrates, contain the microbial secretome with a range of toxins, enzymes and other products secreted by microbes that may play a role in pathogenesis (Mc Namara et al. 2017; Kosanović et al. 2019).

The aim of the work presented here was to characterise the proteomic interactions between (i) A. bisporus and $B$. velezensis, and (ii) T. aggressivum and B. velezensis. 


\section{Material and methods}

Fungal cultures

T. aggressivum f. europaeum 100,526 (acquired from the Westerdijk Institute, Royal Netherlands Academy of Arts and Science, Ultrecht, Netherlands) preserved in liquid nitrogen culture collection of Maynooth University and A. bisporus commercial strain A15 (Sylvan Inc., France) were used in this study. Trichoderma stocks were maintained on malt extract (ME) agar (Oxoid). A. bisporus was maintained as spawn (sterilized rye grains colonised with A. bisporus) and on CYM agar plates.

\section{Bacterial cultures}

Algoriphagus sp., Sphingopyxis sp., Nocardioides sp., $B$. velezensis (isolated from mushroom growing substrate - Teagasc, Ireland), B. subtilis MU Prep lab and B. velezensis QST 713 (Serenade ${ }^{\circledR}$ - Bayer) were used in this study. Bacterial stocks were maintained on nutrient agar (NA) (Oxoid).

Isolation and identification of bacteria from mushroom casing in a production environment

Bacteria were isolated from mushroom casing, a mixture of peat and lime (Harte Peat Ltd., Ireland), taken from a crop in cultivation at the Teagasc Mushroom Growing Unit (Ashtown, Dublin, Ireland). Compost bacteria are known to migrate from compost to casing (Grewal and Rainey 1991). Also, growers sometimes mix some compost into the casing (CAC techniqueCompost Added at Casing) (MacCanna and Flanagan 1972) and thus increase the process of casing colonization via microorganisms (at Teagasc Mushroom growing facility the same technique has been performed). Isolates were maintained on nutrient agar (NA) (Oxoid). 16S rRNA gene sequencing was used to identify the selected colonies. PCR analysis was carried out with V3 and V4 region of bacterial 16S rRNA, using forward: 5' TCGTCGGCAGCGTCAGATGTGTATAA GAGACAGCCTACGGGNGGCWGCAG3' and reverse: 5'GTCTCGTGGGCTCGGAGATGTGTATA AGAGACAGGACTACHVGGGTATCTAATCC3' primers (Klindworth et al. 2013) for amplification of the gene. Each $50 \mu \mathrm{L}$ reaction mixture consisted of $10 \mu \mathrm{l}$ Reaction buffer, $1 \mu \mathrm{l}$ of $10 \mu \mathrm{M}$ forward and reverse primers, $0.5 \mu \mathrm{l}$ of Taq polymerase, $3 \mu \mathrm{l}$ of sample and $34.5 \mu$ of $\mathrm{dH}_{2} \mathrm{O}$. A sample free $\left(\mathrm{dH}_{2} \mathrm{O}\right.$ substitute $)$ reaction mixture was used as a negative control. Initial denaturation of samples was carried out at $95{ }^{\circ} \mathrm{C}$ for $3 \mathrm{~min}$, followed by 35 cycles of denaturation at $95^{\circ} \mathrm{C}$, primer annealing at $55^{\circ} \mathrm{C}$ and extension at $72{ }^{\circ} \mathrm{C}$ all for $30 \mathrm{~s}$ with the final extension at $72{ }^{\circ} \mathrm{C}$ for $5 \mathrm{~min}$. Five $\mu \mathrm{l}$ of PCR products were separated by electrophoresis in $1 \%$ agarose gel, stained with SYBR safe and visualized with a G-BOX (Syngene, UK). The clean-up of PCR products was carried out on a magnetic plate using KAPA Pure Beads (Roche), washed two times in $70 \%$ Ethanol and resuspended in Elution buffer. The concentration and quality of isolated DNA was evaluated using a DeNovix DS-11 spectrophotometer (A260/A280 ratio). Sequencing was performed by Eurofins Genomics Sequencing GMBH (Germany). The obtained sequences were analyzed using BLAST (https://blast. ncbi.nlm.nih.gov/Blast.cgi) and prepared for deposition to NCBI (National Centre for Biotechnology Information) GenBank database by BioEdit program. GenBank accession numbers for deposited nucleotide sequences were assigned (Table S1).

Additional sequencing was performed to verify the identity of $B$. velezensis, $16 \mathrm{~S}$ rRNA whole gene analysis and gyrB gene analysis by Charles River laboratory (France) (Fig. S1 \& S2).

Antagonistic assay

Ten microliter drops of a bacterial overnight broth culture were transferred onto NA and YMEA (yeast malt extract agar), $2 \mathrm{~g} \mathrm{~L}^{-1}$ yeast extract, $20 \mathrm{~g} \mathrm{~L}^{-1}$ malt extract, $15 \mathrm{~g} \mathrm{~L}^{-1}$ agar, (Pandin et al. 2018) plates inoculated with $10^{4}$ T. aggressivum conidia and incubated for $48 \mathrm{~h}$ at $25{ }^{\circ} \mathrm{C}$. Following this, the plates were examined for zones of inhibition around the $10 \mu$ bacterial culture drops. Nutrient broth (NB) was used as a negative control.

Assessment of effect of bacterial supernatants on wet weight of T. aggressivum

Bacterial cultures were grown in nutrient broth (NB) (Oxoid) at $30{ }^{\circ} \mathrm{C}$ until the stationary phase was reached, then centrifuged and filter-sterilized through $0.2 \mu \mathrm{m}$ syringe filters to produce supernatants. Cultures (50 ml) of T. aggressivum $10^{4}$ conidia/ml were grown 
for $24 \mathrm{~h}$ at $30{ }^{\circ} \mathrm{C}$ and $200 \mathrm{rpm}$ in ME broth and then supplemented with bacterial (Algoriphagus sp., Sphingopyxis sp., Nocardioides sp., Bacillus spp.) stationary phase supernatant to give a final concentration of $25 \% \mathrm{v} / \mathrm{v}$ and incubated for an additional $24 \mathrm{~h}$ under the same conditions. Cultures were harvested by centrifugation at $4143 \times \mathrm{g}$ for $15 \mathrm{~min}$. The supernatant was discarded, and wet mass was measured.

Effect of B. velezensis supernatant on A. bisporus growth

Cultures $(50 \mathrm{ml}$ ) of A. bisporus (one spawn grain of A15 in CYM broth) were grown for 8 days in CYM broth at $25{ }^{\circ} \mathrm{C}$ and $200 \mathrm{rpm}$ and supplemented with $25 \% \mathrm{v} / \mathrm{v}$ bacterial supernatant for an additional 2-days at $25^{\circ} \mathrm{C}$. A. bisporus mycelium was harvested by centrifugation at $4143 \times \mathrm{g}$ for $15 \mathrm{~min}$. The supernatant was discarded, and wet mass was measured.

\section{LFQ proteomics of T. aggressivum and A. bisporus} treated with $B$. velezensis supernatant

Proteins were extracted according to Maher et al. (2018) from $A$. bisporus mycelium which was grown for 8-days and then supplemented with $B$. velezensis supernatant $(n=3)$ for an additional 2-days. Proteins were also extracted from $T$. aggressivum mycelium which was grown for $24 \mathrm{~h}$ and then supplemented with $B$. velezensis supernatant $(\mathrm{n}=3)$ for an additional $24 \mathrm{~h}$. The Bradford method was used to quantify proteins for acetone precipitation overnight. Samples were centrifuged at $14500 \times \mathrm{g}$ for $10 \mathrm{~min}$, and the pellet was resuspended in $25 \mu \mathrm{l}$ of $6 \mathrm{M}$ urea, $2 \mathrm{M}$ thiourea and $0.1 \mathrm{M}$ Tris- $\mathrm{HCl}$ buffer $(\mathrm{pH} 8.0)$. Proteins were reduced with dithiothreitol (0.5 M DTT), alkylated with iodoacetamide (0.55 M IAA) and digested with sequence grade trypsin (Promega, Ireland) at a trypsin: protein ratio of $1: 40$, overnight at $37{ }^{\circ} \mathrm{C}$. Tryptic peptides were purified for mass spectrometry using $\mathrm{C} 18$ spin columns (Medical Supply Company, Ireland) and $0.75 \mu \mathrm{g}$ of peptide mix was eluted onto a QExactive (ThermoFisher Scientific, USA) high resolution accurate mass spectrometer connected to a Dionex Ultimate 3000 (RSLCnano) chromatography system. Peptides were separated by an increasing acetonitrile gradient from $2 \%-40 \%$ on a Biobasic C18 Picofrit column (100 mm length, $75 \mathrm{~mm}$ ID), using a 120 -min reverse phase gradient at a low rate of $250 \mathrm{nl} / \mathrm{min}$. A full $\mathrm{MS}$ scan of range 200-2000 was followed to select the 15 most intense ions prior to MS/MS. Identification of proteins from this data was performed using the Andromeda search engine in Max-Quant (version 1.2.2.5) to correlate against an A. bisporus and T. aggressivum database downloaded from www.uniprot.org.

The MS proteomic data and MaxQuant search output files have been added to the ProteomeXchange Consortium (Perez-Riverol et al. 2019) via the PRIDE partner repository with the dataset identifier PXD017970. The Perseus software package (v. 1.5.5.3) was used for results processing, statistical analyses and graphics generation. LFQ intensities were $\log 2$-transformed and ANOVA of significance and t-tests between the treated groups was performed using a $p$ value of 0.05 and significance was determined using FDR correction (Benjamini and Hochberg 1995). Proteins which had non-existent values (suggestive of absence or very low abundance in a sample) were also used in statistical analysis. Proteins found to be absent (below the level of detection) in one or more treatments and present (above the level of detection) in three or fewer treatments were also used in statistical analysis of the total differentially expressed group following imputation of the zero values with values that simulate low abundant proteins.

These proteins were subjected to Gene Ontology (GO) analysis by Blast2GO software tool (https://www.blast2go.com/). Statistically enriched GO descriptors were examined to identify clusters of proteins enriched within statistically significant differentially abundant (SSDA) protein lists $(p<0.05)$.

The Search Tool for the Retrieval of INteracting Genes/Proteins (STRING) v10.5 (http://string-db.org/) was used to map known and predicted protein:protein interactions. UniProt gene lists (extracted from Perseus) were inputted and analyzed in STRING using the medium confidence $(0.5)$ setting to produce interactive protein networks for proteins increased and decreased in abundance.

\section{Statistical analysis}

Proteomic and yield experiments were carried out in three replicates and results are expressed as the mean \pm SE. ANOVA and t-tests with significant differences were considered at $p<0.05$ (Prism 5.0, GraphPad Software, Inc.). 


\section{Results}

Bacterial identification

A range of bacteria was isolated from the mushroom casing and cultivated on NA (Oxoid). Four individuals were selected for further study: Algoriphagus sp., Sphingopyxis sp., Nocardioides sp. and B. velezensis. Bacterial amplicons were deposited in GenBank database and analyzed by BLAST program (Table S1). B. velezensis QST 713 (Serenade ${ }^{\circledR}$ - Bayer) and a $B$. subtilis isolate from Maynooth University Prep Laboratory were also included in this study. B. velezensis (Fig. S1 \& S2) deposited in GenBank under MT156336, is the main focus of this study.

Antagonistic test

B. velezensis produced a zone of inhibition (radius = $8.2 \mathrm{~mm}$ ) on NA agar plates inoculated with $10^{4}$ T. aggressivum conidia after $48 \mathrm{~h}$ (Fig. S3a). Two of the mushroom casing bacteria identified in this study had no inhibitory effect, while Sphingopyxis sp., B. velezensis QST 713 and B. subtilis (MU Prep Lab) produced zones of inhibition of $36.18 \pm 2.2,67.86 \pm 5.1$ and $32.8 \pm 2.9 \mathrm{~mm}^{2}$, respectively when incubated on NA plates (Fig. S3a). Further tests performed on YMEA and NA plates at $25{ }^{\circ} \mathrm{C}$ showed that $B$. velezensis and $B$. velezensis QST 713 produced an area of inhibition $196.6 \pm 19.5 \mathrm{~mm}^{2}$ and $309.0 \pm 46.0 \mathrm{~mm}^{2}$ on YMEA, respectively (Fig. S3b). B. subtilis produced no area of inhibition on YMEA or NA media (Fig. S3b).

Effect of $B$. velezensis supernatant on $T$. aggressivum growth

The effect of bacterial supernatants on T. aggressivum growth was assessed after $48 \mathrm{~h}$ by measuring the wet mass of the $T$. aggressivum mycelium. The $B$. velezensis supernatant $(25 \% \mathrm{v} / \mathrm{v})$ produced the greatest inhibition of T. aggressivum wet mass (Fig. S4) and in a subsequent trial containing $B$. velezensis supernatant T. aggressivum growth was $2.9 \pm 0.3 \mathrm{~g}$ compared to the control $4.6 \pm 1.0 \mathrm{~g}(P=0.15, \mathrm{df}=6, \mathrm{t}=1.7)$ (Fig. 1a). Since the B.velezensis isolate produced the greatest inhibition of mycelial growth it was selected for subsequent analysis.
Effect of $B$. velezensis supernatant on A. bisporus growth

The effect of $B$. velezensis supernatant on A. bisporus growth was assessed after an initial 8-day incubation of A. bisporus at $25^{\circ} \mathrm{C}$ and an additional 2-days of coincubation with $25 \% \mathrm{v} / \mathrm{v}$ B. velezensis filter-sterilized supernatant or NB (control). B. velezensis supernatant did not show any effect on the growth of $A$. bisporus mycelia. Average wet mass for the control was $5.1 \mathrm{~g} \pm$ 0.7 and for the treatment was $5.2 \mathrm{~g} \pm 1.2$ (Fig. 1b). There was no statistical difference between control and treatment samples $(P=0.95, \mathrm{df}=6, \mathrm{t}=0.07)$. The material was used for further proteomic analyses.

Proteomic analysis of response of $T$. aggressivum after exposure to $B$. velezensis supernatant

In total 9942 peptides were identified, representing 863 proteins, following exposure of $T$. aggressivum to $B$. velezensis. According to Perseus analysis a total of 417 T. aggressivum proteins in the $B$. velezensis treatment were determined to be differentially abundant (analysis of variance [ANOVA], $P<0.05$ ), 89 increased and 328 decreased in relative abundance with a fold change value of $>2$.

A principal-component analysis (PCA) performed on all filtered proteins distinguished the control and $B$. velezensis-treated samples, indicating a clear difference between the proteomes (Fig. S5). T. aggressivum control group (unchallenged) and T. aggressivum treated with $B$. velezensis supernatant showed clear differences based on hierarchical clustering of proteins increased in one group and decreased in another (Fig. S6). The clear difference in protein abundance similarities based on hierarchical clustering between the control group of T. aggressivum vs T. aggressivum treated with $B$. velezensis supernatant is further highlighted in Fig. S6. This image shows a heat map constructed using the data gathered from label-free proteomic analysis of T. aggressivum control vs. T. aggressivum treated with $B$. velezensis supernatant. Indicating that specific bunches of proteins that are increased in abundance in one group are decreased in another and vice versa, further pointing to the influence that the supernatant had on the overall proteome compared to control.

Exposure of $T$. aggressivum to B. velezensis supernatant led to an increase in proteins associated with catabolic processing of amino acids (40-fold), amino 
Fig. 1 a. T. agressivum growth [g] in CYM after $48 \mathrm{~h}$ incubation, containing $25 \% \mathrm{v} / \mathrm{v}$ of either: $\mathrm{NB}$ (Control) or B. velezensis supernatant. $(p=0.15, \mathrm{t}=1.66, \mathrm{df}=6)$. b. A. bisporus growth $[\mathrm{g}]$ in CYM after 8-days incubation at $25^{\circ} \mathrm{C}$, containing $25 \% \mathrm{v} / \mathrm{v}$ of either: $\mathrm{NB}$ (Control) or B. velezensis supernatant for the last 2-days of incubation. $P=0.95, \mathrm{t}=0.066, \mathrm{df}=6$

a

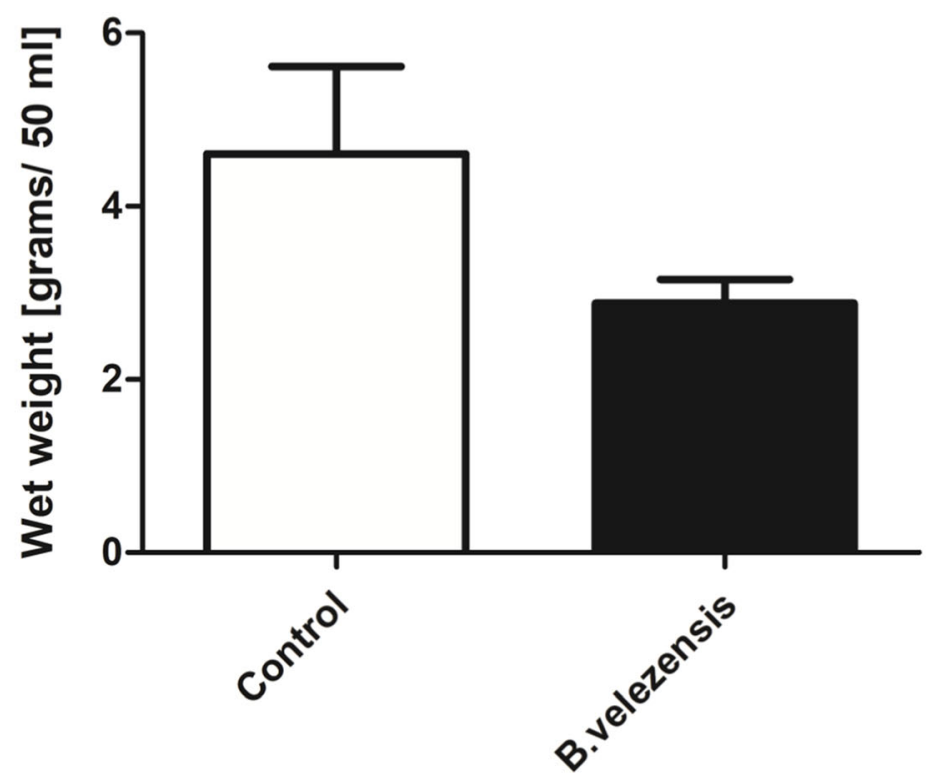

T. aggressivum

b

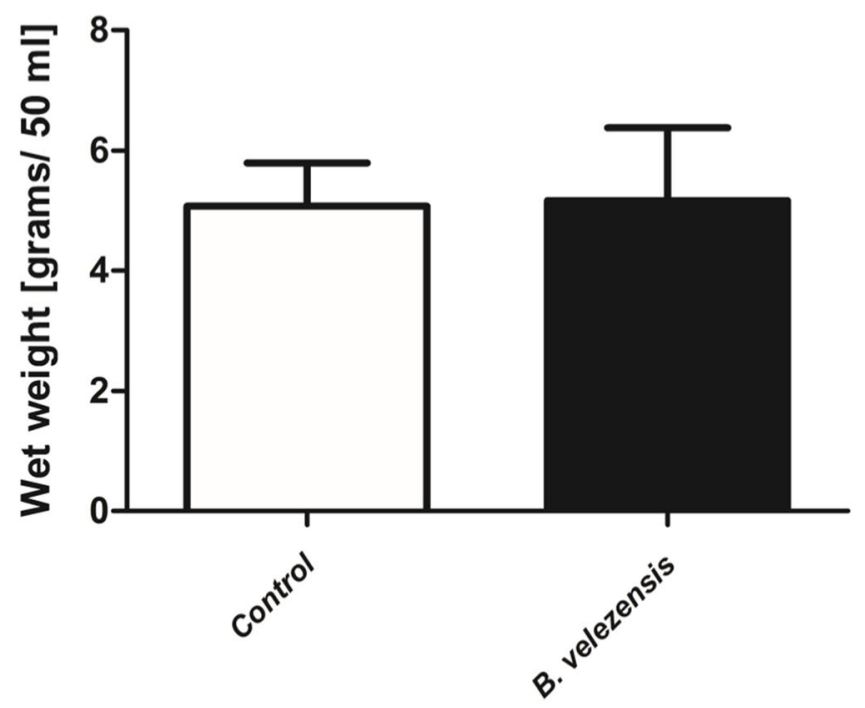

\section{A. bisporus}

oxidase proteins (14-fold), oxidoreductase proteins (13fold, 4-fold) and hydrolases (3-fold). These results suggest that exposure to $B$. velezensis supernatant has a damaging effect on T. aggressivum as proteins associated with the breakdown of essential amino acids increased as did proteins associated with stress (Fig. 2).
In addition to this, exposure of $T$. aggressivum to $B$. velezensis supernatant led to a decrease in the abundance of proteins such as anti-oxidants (29-fold), NTF2 domain containing protein (17-fold), 60S ribosomal protein L-13 (14-fold), glucoamylase proteins (13-fold), proteasome subunit proteins $(11$-fold) and other 
ribosomal proteins (9-fold). This further emphasizes the detrimental effect of $B$. velezensis on T. aggressivum as essential growth proteins and proteins associated with preventing damage in cells decline (Fig. 2).

According to STRING analysis (string-db.org) there was enrichment of protein groups in T. aggressivum sample exposed to B. velezensis supernatant (Fig. 3). Protein groups that were found to have more interactions among themselves were ribosomal, mitochondrial, catabolic, dehydrogenase and proteolytic proteins. Ribosomal proteins are involved in growth and development processes that seem to be altered in treated samples, and the mitochondrial cluster shows alteration in oxidase production meaning that the hyphae may have been under stress. Dehydrogenase proteins, and especially detoxification proteins, may be stimulated as a defense mechanism. Proteolysis breakdown of proteins into polypeptides or amino acids is also noted.

Proteins were subjected to Gene Ontology (GO) analysis by Blast2GO software tool (Fig. S7 a, b, c, d). Several GO terms belonging to biological process (oxidation-reduction and organic substance metabolic process), molecular function (ion binding, oxidoreductase activity), cellular component (intracellular organelle, membrane and cytoplasm) were significantly enriched within the $B$. velezensis group dataset. Hydrolases, oxidoreductases and transferases were the most enriched enzymes with hydrolases being the most abundant in $B$. velezensis challenged group. Indicating oxidative stress response.

Proteomic analysis of response of $A$. bisporus after exposure to $B$. velezensis

Following exposure to A. bisporus to B. velezensis supernatant a total 619 peptides were identified, representing 81 proteins. According to Perseus analysis a total of 12 A. bisporus proteins in the B. velezensis treatment were determined to be differentially abundant (analysis of variance [ANOVA], $P<0.05$ ), 1 increased and 11 decreased in relative abundance with a fold change value of $>2$.

A principal-component analysis (PCA) performed on all filtered proteins distinguished the control and B. velezensis treated samples (Fig. S8). Even though difference between control and treatment group proteomes exists these groups are close, suggesting less alteration in proteins between control and treatment groups.

Exposure of Agaricus bisporus to B. velezensis supernatant led to a decrease in proteins such as Prohibitin which plays a role in cell survival (13-fold, 6-fold), proteasomal proteins (11-fold), signaling proteins such as cytosolic adaptor domain containing protein (5-fold), aldehyde dehydrogenase which plays a role in cell detoxification (4-fold), ribosomal proteins (4-fold), DLH domain-containing protein (4-fold) and proteins involved in secondary metabolism such as PKS_ER domain containing protein (3-fold) (Fig. 4). The downregulation of such proteins suggests that A. bisporus was not put under any stress upon contact with $B$. velezensis supernatant.

Only one protein was over-expressed in a statistically significant way (2-fold) but was found to be uncharacterized (Fig. 4). Combined, these results suggest that $B$. velezensis has no adverse effects on $A$. bisporus, a potentially useful result if $B$. velezensis was to be considered as a biocontrol against fungal pathogens of button mushrooms.

\section{Discussion}

Effective biocontrol agents are urgently required globally as many chemical fungicides are being withdrawn or phased out. Reasons include pathogens developing resistance, chemicals being deactivated in substrates, toxicity to crops, and toxicity to non-target organisms (Grogan and Gaze 2000; Romaine et al. 2005; Gea et al. 2005; Grogan 2006; Potočnik et al. 2015; Stanlet and Preetha 2016). Hence, there is an intense focus placed on the discovery of novel, superior biocontrol bacteria (Potočnik et al. 2019).

Serenade $\AA$ is Bayer's biocontrol agent containing non-pathogenic Bacillus velezensis (originally identified as B. subtilis) strain QST 713 for the treatment of fungal diseases in agricultural crops. Only a limited number of similar products are available on the commercial market. It contains compounds with multiple mechanisms of action, which makes resistance less likely. Bacillus velezensis strain QST 713 releases compounds such as lipopeptides which penetrate cell membranes of pathogenic cells, causing the cells to become leaky, allowing the entry of other anti-fungal compounds and resulting in cell death (Marrone 2002). 


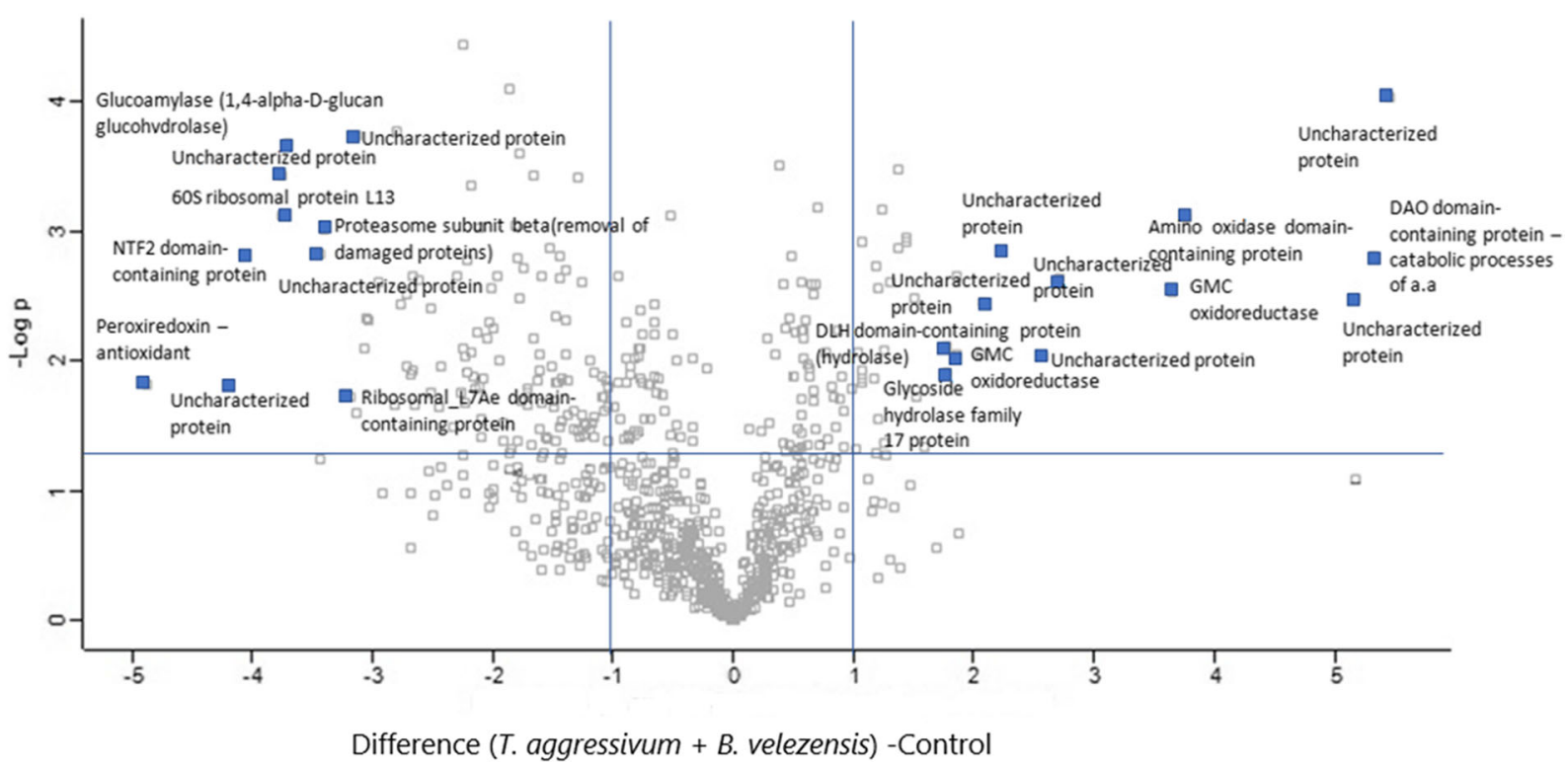

Fig. 2 Proteomic responses of T. aggressivum cultivated for $24 \mathrm{~h}$ and co-incubated with $25 \% \mathrm{v} / \mathrm{v}$ supernatant of. B. velezensis for additional $24 \mathrm{~h}$. Volcano plot represents protein intensity difference ( $-\log 2$ mean intensity difference) and significance in differences ( $-\log P$ value) based on a two-sided t-test. Proteins above

Improvement of white mushroom yield following use of a Bacillus sp. has been reported by Tautorus and Townsley (1983). Bacillus sp. added to A. bisporus compost significantly improved the mycelial growth and was effective with olive green mould (Chaetomium olivaceum) control. Védie and Rousseau (2008) described efficacy of Serenade ${ }^{\circledR}$ against Trichoderma sp. Recent studies also showed the efficacy of B. velezensis in vivo trials (Pandin et al. 2018). Elsewhere, Nagy et al. (2012) observed that B. amyloliquefaciens (species used in Serifel $($ ) was effective in vivo against $T$. pleurotum, the causal agent of green mould on oyster mushroom, and that it improved the mushroom yield $(+10 \%)$. Kosanović et al. (2013) found that B. velezensis QST 713 (strain used in Serenade ${ }^{\circledR}$ ) was highly toxic (in vitro) to all tested Trichoderma isolates from mushroom growing sites (ED50 values were below $1.3 \mathrm{mgL}^{-1}$ ): T. aggressivum f. europaeum, T. harzianum, T. atroviride, T. koningii and $T$. virens. In a subsequent in vivo trial, a mixture of fungicide and biocontrol agent (80:20, prochloraz: Serenade $($ ) was applied in the mushroom growing room and an antagonistic interaction was found between prochloraz and Serenade ${ }^{\circledR}$ regarding mushroom productivity. Disease symptoms were better prevented with individual treatments compared to their mixtures. the line are considered statistically significant $(p$ value $<0.05$ ) and those to the right and left of the vertical lines indicate relative fold changes $>2$. Annotations are given for the most differentially abundant proteins identified. These plots are based upon post imputed data

Therefore, Serenade ${ }^{\circledR}$ showed better disease control when it was applied alone than its mixture with the fungicide. However, Serenade ${ }^{\circledR}$ decreased mushroom yield in this trial compared to the controls (uninoculated and inoculated with T. harzianum) and the prochloraz fungicide treatment (Kosanović et al. 2013).

Bacillus species are generally considered as effective biocontrol agents due to inhibitory metabolites such as cell-wall degrading enzymes (Cawoy et al. 2011; Khan et al. 2018), their growth-promoting plant hormones (Akinrinlola et al. 2018; Radhakrishnan et al. 2017; Sansinenea 2019) and ability to induce the equivalent of plant adaptive immunity (Fira et al. 2018). Many Bacillus species display antibiosis - an antagonistic effect towards pathogens (Kim and Chung 2004; Leelasuphakul et al. 2006; Živković et al. 2010; Cawoy et al. 2011; Bacon et al. 2015). Bacillus spp. produce spores that are resistant to various physical and chemical treatments such as heat, desiccation, UV irradiation and organic solvents (Leelasuphakul et al. 2008).

There are major concerns around the treatment of mycopathogens in the mushroom industry as host and pathogen are fungal so any biocontrol agent must show a differential effect in order not to compromise mushroom yield but still control the pathogen. Some Trichoderma spp. are used as biocontrol agents in plant 


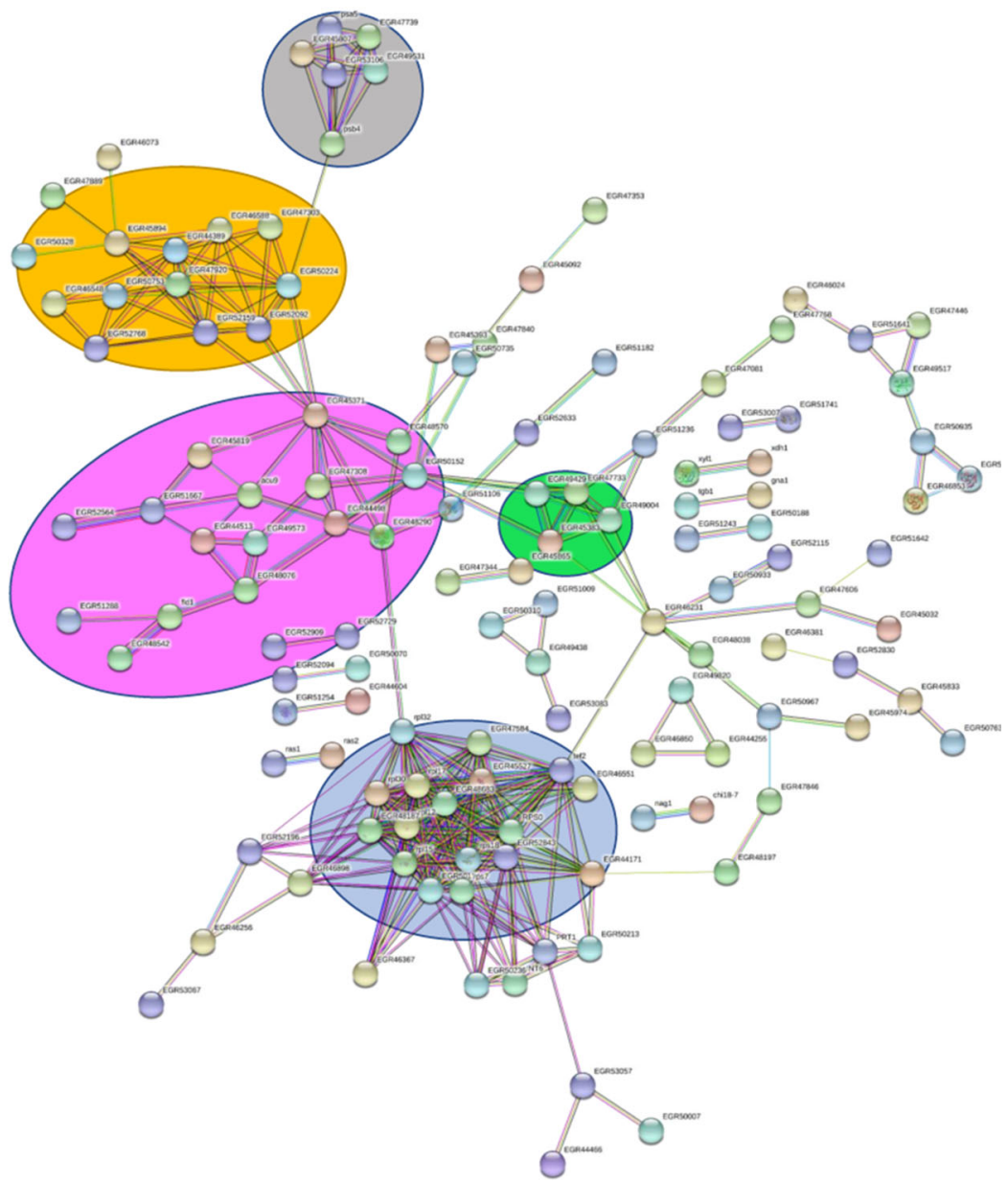

Ribosomal proteins Mitochondrial proteins - ETC, oxidase Amino acid transporters \& catalytic proteins

Dehydrogenase proteins - detoxification Proteolytic proteins (proteosomal proteins)

Fig. 3 STRING analysis showing enrichment of protein groups seen in T. aggressivum sample treated with B. velezensis that have more interactions among themselves

protection (Weindling 1932; Harman et al. 2010; Lorito et al. 2010), but while they may be beneficially used for the control of fungal pathogens of plant-based crops, they are not desirable in mushroom crop production since, not only A. bisporus but Oyster mushroom (Pleurotus ostreatus) and Shiitake (Lentinula edodes) are also prone to Trichoderma infections (Qiu et al. 2017; Wang et al. 2016).

Screening of a variety of bacteria from mushroom compost (Algoriphagus sp., Sphingopyxis sp., Nocardioides sp., Bacillus sp) and comparing with commercial bacteria (B. velezensis QST 713, Serenade ${ }^{\circledR}$ Bayer) led to identification of one Bacillus sp., $B$. velezensis, that inhibited $T$. aggressivum growth and $\operatorname{did}$ not affect $A$. bisporus.

Isolated $B$. velezensis produced the highest zone of inhibition on NA plates (radius $=8.2 \mathrm{~mm}$, Fig. S3) and its supernatant inhibited the biomass production of T. aggressivum (Fig. 1a, - 37\%; Fig. S4). A principalcomponent analysis distinguished the control and $B$. velezensis -treated samples, indicating a clear difference between the proteomes (Fig. S5). The Heat map showed that proteins increased in abundance in control are decreased in $T$. aggressivum treated with $B$. velezensis and vice versa, pointing to the influence of $B$. velezensis supernatant on $T$. aggressivum proteome (Fig. S6). Further, label free proteomic analysis indicated that $T$. aggressivum showed an increased abundance in stress response proteins, oxidoreductase (14-fold, 13-fold and 4-fold) and hydrolase (3-fold), and a strong increase in abundance of proteins associated with catabolic processing of essential amino acids (40fold) (Fig. 2).On the other hand, exposure of $T$. aggressivum to $B$. velezensis supernatant led to a 


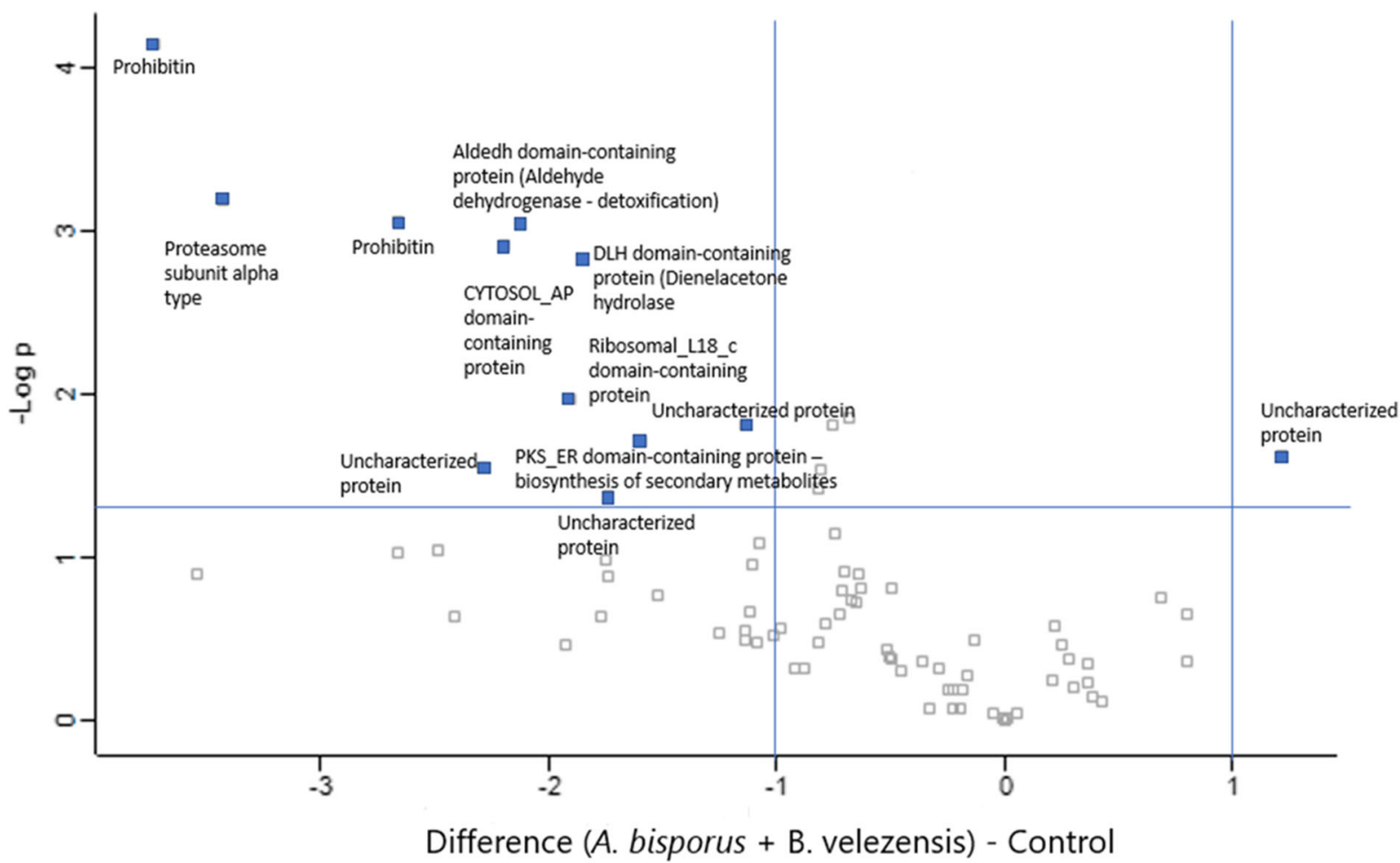

Fig. 4 Proteomic responses of $A$. bisporus cultivated for 8 days and co-incubated with $25 \% \mathrm{v} / \mathrm{v}$ supernatant of $B$. velezensis for additional $48 \mathrm{~h}$. Volcano plot represents protein intensity difference $(-\log 2$ mean intensity difference) and significance in differences ( $-\log \mathrm{P}$ value) based on a two-sided t-test. Proteins above

reduction in the abundance of proteins associated with growth such as $60 \mathrm{~S}$ ribosomal protein L-13 (14-fold) and other ribosomal proteins (9-fold). Also, antioxidants (29-fold), NTF2 domain containing protein (17-fold), glucoamylase proteins (13-fold) and proteasome subunit proteins (11-fold) were decreased (Fig. 2). Gene Ontology analysis supported oxidative stress response in B. velezensis treated group (Fig. S7 a, b, c, d). While, STRING analysis showed ribosomal proteins, mitochondrial stress response, detoxification defense mechanism and catabolic processes of proteins, polypeptides and amino acids to be active (Fig. 3). All these results indicate that exposure of T. aggressivum to $B$. velezensis supernatant cause growth inhibition of mycopathogenic T. aggressivum and the induction of an oxidative stress response in the fungal cells.

In contrast, exposure of $A$. bisporus to $B$. velezensis supernatant showed no effect on A. bisporus. Biomass growth was slightly stimulated after co-incubation with B. velezensis supernatant (Fig. $1 \mathrm{~b},+\mathbf{2 \%}$ ). A principal- the line are considered statistically significant ( $p$ value $<0.05$ ) and those to the right and left of the vertical lines indicate relative fold changes $>2$. Annotations are given for the most differentially abundant proteins identified. These plots are based upon post imputed data

component analysis performed on all filtered proteins distinguished the control and $B$. velezensis -treated samples but also found this group proteomes are very close (Fig. S8). LFQ proteomic examination shows that A. bisporus was not under stress upon contact with B. velezensis supernatant (Fig. 4) - no decrease in growth and no stress induced proteins were evident. Exposure of $A$. bisporus to B. velezensis supernatant has led to a decrease in protein which plays a role in cell survival: prohibitin (13-fold, 6-fold), secondary metabolism: PKS_ER domain containing protein (3-fold) and cell detoxification: aldehyde dehydrogenase (4fold) (Fig. 4). The down-regulation of such proteins, suggests that $A$. bisporus was not under stress upon contact with $B$. velezensis supernatant.

The results obtained by an in vitro experimental design may not reflect the $A$. bisporus crop environment and further in vivo trials with the culture supernatant are essential to potentially confirm the in vitro results. The use of the culture supernatant, instead of the whole 
bacterium, might be beneficial since it does not depend on survival of the bacterium within the microbial community of the cropping system.

\section{Conclusion}

B. velezensis showed favourable characteristics to be considered as a future biocontrol agent as it affects the mycopathogen ( $T$. aggressivum) but does not produce any damage to the white mushroom (A. bisporus). Further testing of $B$. velezensis supernatants is required, both in mushroom growing test unit and in laboratory, to identify, purify and concentrate the specific components of the secretomes that play a role in pest control. In vivo trials with the culture supernatant are essential to potentially confirm the in vitro results.

Supplementary Information The online version contains supplementary material available at https://doi.org/10.1007/s10658021-02252-5.

Acknowledgments DK is a Postdoctoral Fellow supported by Irish Research Council, GOIPD/2018/115. Q-Exactive mass spectrometer was funded under the SFI Research Infrastructure Call 2012; Grant Number: 12/RI/2346. Dr. Thi Thuy Do, Maynooth University Antimicrobial Resistance and Microbiome Research Group, for helping with DNA extraction, sequencing, and identification.

Declarations This article does not contain any study with human participants or animals.

Conflict of interest The authors have no conflicts of interest to declare.

\section{References}

Akinrinlola, R. J., Yuen, G. Y., Drijber, R. A., \& Adesemoye, A. O. (2018). Evaluation of Bacillus strains for plant growth promotion and predictability of efficacy by in vitro physiological traits. International Journal of Microbiology, 2018, 1-11. https://doi.org/10.1155/2018/5686874.

Alexander, S. (2015). Horticulture in Ireland. Teagasc Research, $10(3), \quad 18-19 \mathrm{https}: / / \mathrm{ww}$ w.teag a s c. ie/media/website/publications/2015/TResearch-Autumn-15.pdf.

Anon, (2009). Directive 2009/128/EC of the European Parliament and of the Council of 21 October 2009, establishing a framework for Community action to achieve the sustainable use of pesticides. https://eur-lex.europa.eu/legalcontent/EN/TXT/HTML/?uri=CELEX:02009L012820091125\&from $=\mathrm{EN}$

Bacon, C.W., Palencia, E.R., Hinton, D.M. (2015). Abiotic and biotic plant stress-tolerant and beneficial secondary metabolites produced by Endophytic Bacillus species, In: Arora, N.K. (Ed.), Plant microbes Symbiosis: Applied facets. Springer India, New Delhi, (pp. 163-177). https://doi. org/10.1007/978-81-322-2068-8_8.

Benjamini, Y., \& Hochberg, Y. (1995). Controlling the false discovery rate: A practical and powerful approach to multiple testing. Journal of the Royal Statistical Society, Series B, 57(1), 289-300.

Cawoy, H., Bettiol, W., Fickers, P., Onge, M. (2011). Bacillusbased biological control of plant diseases, in: Stoytcheva, M. (Ed.), Pesticides in the modern world - pesticides use and management. InTech.

Cho, W. C. S. (2007). Proteomics technologies and challenges. Genomics, Proteomics \& Bioinformatics, 5, 77-85. https://doi.org/10.1016/S1672-0229(07)60018-7.

Fira, D., Dimkić, I., Berić, T., Lozo, J., \& Stanković, S. (2018). Biological control of plant pathogens by Bacillus species. Journal of Biotechnology, 285, 44-55.

Fletcher, J.T., Yarham, D.J. (1976). The incidence of benomyl tolerance in Verticillium fungicola, Mycogone perniciosa and Hypomyces rosellus in mushroom crops. Annals of Applied Biology. 84, 343-353.

Gea, F. J., Navarro, M. J., \& Tello, J. C. (2005). Reduced sensitivity of the mushroom pathogen Verticillium fungicola to prochloraz-manganese in vitro. Mycological Research, 109, 741-745.

Grewal, S. I. S., \& Rainey, P. B. (1991). Phenotypic variation of Pseudomonas putida and P. tolizasii affects the chemotactic response to Agaricus bisporus mycelial exudate. Journal of General Microbiology., 137, 2761-2768.

Grogan, H. M. (2006). Fungicide control of mushroom cobweb disease caused by Cladobotryum strains with different benzimidazole resistance profiles. Pest Management Science, 62(2), 153-161. https://doi.org/10.1002/ps.1133.

Grogan, H.M. (2008). Challenges facing mushroom disease control in the 21st century. Mushroom biology and mushroom products. Proceedings of the Sixth International Conference on Mushroom Biology and Mushroom Products, Bonn, Germany: WSMBMP, (pp. 120-127).

Grogan, H. M., \& Gaze, R. H. (2000). Fungicide resistance among Cladobotryum spp.: Causal agent of cobweb disease of the edible mushroom Agaricus bisporus. Mycology Research, 104, 357-364.

Harman, G. E., Obregón, M. A., Samuels, G., \& Lorito, M. (2010). Changing models of biocontrol in the developing and developed world. Plant Disease, 94(8), 928-939.

Khan, N., Martínez-Hidalgo, P., Ice, T. A., Maymon, M., Humm, E. A., Nejat, N., Sanders, E. R., Kaplan, D., \& Hirsch, A. M. (2018). Antifungal activity of Bacillus species against Fusarium and analysis of the potential mechanisms used in biocontrol. Frontiers in Microbiology, 9, 23-63. https://doi. org/10.3389/fmicb.2018.02363.

Kosanović, D., Potočnik, I., Duduk, B., Vukojević, J., Stajić, M., Rekanović, E., \& Milijašević-Marčić, S. (2013). Trichoderma species on Agaricus bisporus farms in Serbia 
and their biocontrol. The Annals of Applied Biology, 163, 218-230.

Kosanović, D., Potočnik, I., Vukojević, J., Stajić, M., Rekanović, E., Stepanović, M., \& Milijašević-Marčić, S. (2015). Fungicide sensitivity of Trichoderma spp. from Agaricus bisporus farms in Serbia. Journal of Environmental Science and Health, Part B, 50(8), 607-613. https://doi.org/10.1080 /03601234.2015.1028849.

Kosanović, D., Sheehan, G., Grogan, H., \& Kavanagh, K. (2019). Characterisation of the interaction of Pseudomonas putida and Pseudomonas tolaasii with Trichoderma aggressivum. European Journal of Plant Pathology, 156, 111-121. https://doi.org/10.1007/s10658-019-01867-z.

Klindworth, A., Pruesse, E., Schweer, T., Peplies, J., Quast, C., Horn, M., \& Glöckner, F. O. (2013). Evaluation of general 16S ribosomal RNA gene PCR primers for classical and next-generation sequencing-based diversity studies. Nucleic Acids Research, 41(1), e1. https://doi.org/10.1093 /nar/gks808.

Kim, P., \& Chung, K. C. (2004). Production of an antifungal protein for control of Colletotrichum lagenarium by Bacillus amyloliquefaciens MET0908. FEMS Microbiology Letters, 234, 177-183.

Leelasuphakul, W., Sivanunsakul, P., \& Phongpaichit, S. (2006). Purification, characterization and synergistic activity of $\beta-1$, 3 -glucanase and antibiotic extract from an antagonistic Bacillus subtilis NSRS 89-24 against rice blast and sheath blight pathogens. Enzyme and Microbial Technology, 38, 990-997.

Leelasuphakul, W., Hemmanee, P., \& Chuenchitt, S. (2008). Growth inhibitory properties of Bacillus subtilis strains and their metabolites against the green mold pathogen (Penicillium digitatum Sacc.) of citrus fruit. Postharvest Biology and Technology, 48, 113-121.

Lorito, M., Woo, S. L., Harman, G. E., \& Monte, E. (2010). Translational research on Trichoderma: From 'omics to the field. Annual Review of Phytopathology, 48, 395-417. https://doi.org/10.1146/annurev-phyto-073009-114314.

MacCanna, C., \& Flanagan, J. B. (1972). Casing types and techniques. Mushroom Science, 3, 727-731.

Maher, A., Staunton, K., \& Kavanagh, K. (2018). Analysis of the effect of temperature on protein abundance in Demodexassociated Bacillus oleronius. Pathogens and Disease, 76. https://doi.org/10.1093/femspd/fty032.

Marrone, P. G. (2002). An effective biofungicide with novel modes of action. Pesticide Outlook, 13, 193-194.

Mc Namara, L., Carolan, J. C., Griffin, C. T., Fitzpatrick, D., \& Kavanagh, K. (2017). Analysis of the effect of entomopathogenic fungal culture filtrate on the immune response of the greater wax moth. Galleria mellonella. Journal of Insect Physiology, 100, 82-92.

Nagy, A., Manczinger, L., Tombácz, D., Hatvani, L., Gyõrfi, J., Antal, Z., Sajben, E., Vágvõllgyi, C., \& Kredics, L. (2012). Biological control of oyster mushroom green mould disease by antagonistic Bacillus species. Biological Control of Fungal and Bacterial Plant Pathogens. IOBC-WPRS Bulletin, 78, 289-293.

Perez-Riverol, Y., Csordas, A., Bai, J., Bernal-Llinares, M., Hewapathirana, S., Kundu, D.J., Inuganti, A., Griss, J., Mayer, G., Eisenacher, M., Pérez, E., Uszkoreit, J., Pfeuffer, J., Sachsenberg, T., Yilmaz, S., Tiwary, S., Cox,
J., Audain, E., Walzer, M., Jarnuczak, A.F., Ternent, T., Brazma, A., Vizcaíno, J.A. (2019). The PRIDE database and related tools and resources in 2019: improving support for quantification data. Nucleic Acids Research, 47(1): 442450 (PubMed ID: 30395289).

Pandin, C., Védie, R., Rousseau, T., Le Coq, D., Aymerich, S., \& Briandet, R. (2018). Dynamics of compost microbiota during the cultivation of Agaricus bisporus in the presence of Bacillus velezensis QST713 as biocontrol agent against Trichoderma aggressivum. Biological Control, 127, 39-54. https://doi.org/10.1016/j.biocontrol.2018.08.022.

Potočnik, I., Stepanović, M., Rekanović, E., Todorović, B., \& Milijašević-Marčić, S. (2015). Disease control by chemical and biological fungicides in cultivated mushrooms: Button mushroom, oyster mushroom and shiitake. Journal of Pesticides and Phytomedicine, 30(4), 201-208. https://doi. org/10.2298/PIF1504201P.

Potočnik, I., Rekanović, E., Todorović, B., Luković, J., Paunović, D., Stanojević, O., \& Milijašević-Marčić, S. (2019). The effects of casing soil treatment with Bacillus subtilis Ch-13 biofungicide on green mould control and mushroom yield. Journal of Pesticides and Phytomedicine, 34(1), 53-60. https://doi.org/10.2298/PIF1901053P.

Qiu, Z., Wu, X., Zhang, J., \& Huang, C. (2017). High temperature enhances the ability of Trichoderma asperellum to infect Pleurotus ostreatus mycelia. PLoS One, 12(10), e0187055. https://doi.org/10.1371/journal.pone.0187055.

Radhakrishnan, R., Hashem, A., \& Abd Allah, E. F. (2017). Bacillus: A biological tool for crop improvement through bio-molecular changes in adverse environments. Frontiers in Physiology, 8, 667. https://doi.org/10.3389 /fphys.2017.00667 eCollection 2017.

Romaine, C. P., Royse, D. J., \& Schlagnhaufer, C. (2005). Superpathogenic Trichoderma resistant to Topsin $\mathrm{M}$ found in Pennsylvania and Delaware. Mushroom News, 53, 6-9.

Royse, D.J., Baars, J., Tan, Q. (2017). Current overview of mushroom production in the world. In: Zied DC, Pardo-Giménez a (eds), edible and medicinal mushrooms, 1 st edn. Technology and applications, (pp. 2-13).

Sansinenea, E. (2019). Bacillus Spp.: As plant growth-promoting Bacteria. In book: Secondary metabolites of plant growthpromoting, [ebook] Puebla, Pue, Mexico: Springer nature Singapore Pte ltd. https://doi.org/10.1007/978-981-13-58623_11.

Savoie, J.-M., Foulongne-Oriol, M., Barroso, G., \& Callac, P. (2013). 1 genetics and genomics of cultivated mushrooms, application to breeding of agarics. In F. Kempken (Ed.), Agricultural applications, the Mycota (pp. 3-33). Heidelberg: Springer, Berlin. https://doi.org/10.1007/978-3642-36821-9 1.

Stanlet, J., Preetha, G. (2016). Pesticide toxicity to non-target organisms exposure, Toxicity and Risk Assessment Methodologies. Springer Nature, 531p. https://link.springer. com/content/pdf/10.1007/978-94-017-7752-0.pdf

Tautorus, T. E., \& Townsley, P. M. (1983). Biological control of olive green mold in Agaricus bisporus cultivation. Applied and Environmental Microbiology, 45(2), 511-515.

Védie, R., \& Rousseau, T. (2008). Serenade biofungicide: une innovation mjeure dans les champignonnières françaises pour lutter contre Trichoderma aggressivum, agent de la moisissure verte du compost. La Lettre du CTC, 21, 1-2. 
Wang, G., Cao, X., Ma, X., Guo, M., Liu, C., Yan, L., \& Bian, Y. (2016). Diversity and effect of Trichoderma spp. associated with green mold disease on Lentinula edodes in China. Microbiologyopen, 5(4), 709-718. https://doi.org/10.1002 /mbo3.364.

Weindling, R. (1932). Trichoderma lignorum as a parasite of other soil fungi. Phytopathology, 22, 837-845.
Živković, S., Stojanović, S., Ivanović, Z., Gavrilović, V., Popović, T., \& Balaz, J. (2010). Screening of antagonistic activity of microorganisms against Colletotrichum acutatum and Colletotrichum gloeosporioides. Archives of Biological Sciences, 62(3), 611-623. 